\section{Revista de Letras}

ISSN: 2179-5282

\title{
Estratégias metacognitivas de leitura na escola
}

\section{RESUMO}

\section{Angela Dondoni}

angeladondoni@gmail.com

Universidade do Oeste do Paraná/Seed, Cascavel, Brasil.

Maria Elena Pires dos Santos

mel.pires@hotmail.com

Universidade do Oeste do Paraná

Cascavel, Brasil.
Este artigo busca discutir alguns conceitos referentes a estratégias metacognitivas de leitura, a partir dos resultados de uma pesquisa realizada com professores de diferentes disciplinas de uma escola pública. A pesquisa desenvolvida tinha como intuito averiguar quais estratégias metacognitivas de leitura os professores participantes utilizam durante suas leituras e se estes profissionais ensinam estas estratégias aos educandos. Os resultados foram obtidos por meio de questionário escrito. A pesquisa demostrou que todos os entrevistados utilizam estratégias metacognitivas durante suas leituras, já ao que se refere ao ensino aprendizagem dessas estratégias, esse resultado apresentou variações.

PALAVRAS-CHAVE: Estratégias metacognitivas. Leitura. Ensino. 


\section{INTRODUÇÃO}

O objetivo deste texto é o de apresentar os resultados de uma pesquisa sobre as estratégias de metacognição em leitura utilizadas por professores de um colégio da rede pública estadual, além de explicitar como eles orientam seus alunos a utilizarem essas estratégias para um melhor desempenho na leitura. Os professores que participaram desta pesquisa têm formação superior em diversas áreas do conhecimento, tais como: Língua Portuguesa, Ciências, Geografia, Matemática, Espanhol, Inglês, Arte e História.

A opção por realizar a pesquisa com professores de distintas disciplinas se deu por entendermos que não é responsabilidade apenas do professor de Língua Portuguesa a formação de leitores críticos; antes, esta deve ser uma preocupação de todos os professores, independentemente da disciplina que lecionam. Nesse sentido, corroboramos com a afirmação de Kleiman (2007, p. 23), para quem "[...] o ensino e prática da leitura, atividade constitutiva da aprendizagem, deve fazer parte de todas as atividades, e todo professor é, em última instância, professor de leitura. Dessa forma, nosso propósito com a pesquisa, realizada em forma de questionário escrito, foi o de verificar:

1. De que estratégias os professores participantes lançam mão durante suas leituras para que estas se tornem mais eficientes;

2. Como esses professores preparam seus alunos para utilizarem estratégias metacognitivas durante a leitura.

Antes de respondermos a essas questões, contudo, é necessário esclarecermos alguns conceitos, tais como o de metacognição e de estratégia de leitura, para um melhor entendimento acerca dos pontos que serão abordados neste artigo.

\section{CONCEITO DE METACOGNIÇÃO E DE ESTRATÉGIA}

Entre os autores que discutem o complexo conceito de metacognição, Leffa (1996, p. 46) argumenta que "[...] a metacognição na leitura trata do monitoramento da compreensão feito pelo próprio leitor durante o ato da leitura". Segundo esse mesmo autor, os bons leitores se utilizam de estratégias e, por isso, têm maior consciência de seu comportamento de leitura, sendo capazes de descrevê-las e, ainda, discuti-las.

A utilização da metacognição durante o processo de leitura é característica de um leitor crítico, que "aproxima textos", tem consciência das dificuldades que encontra durante a leitura, tem autonomia para decidir quais estratégias pode utilizar, bem como avalia essas estratégias durante o processo, podendo modificá-las, quando necessário. A partir desta proposição,podemos inferir que utilizar estratégias metacognitivas é monitorar e avaliar a própria leitura. Assim, parafraseando as palavras de Ribeiro (2003), a metacognição, entre tantas coisas, significa ter noção do conhecimento sobre o próprio conhecimento, poder avaliar esse conhecimento e todo o seu processo de aprendizagem e cognição, ou seja: 
do início da tarefa, nos ajustamentos que se fazem enquanto se realiza a tarefa e nas revisões necessárias à verificação dos resultados obtidos. (RIBEIRO, 2007, p. 114).

Dessa forma, a metacognição pode "[...] ser entendida como uma capacidade fundamental da qual depende a aprendizagem, com certeza muito importante, porém muitas vezes não tendo sido trabalhada pela escola" (RIBEIRO, 2003, p.110). É importante, então, que seja ensinada na escola pelos professores e entendida como essencial para o desenvolvimento do educando:

\begin{abstract}
O problema da escola é que se tende a supor, nela, que os alunos já são capazes de operar cognitivamente e, notadamente, de realizar raciocínios dedutivos e indutivos. Com isso, os professores se sentem liberados da tarefa de ensinar a pensar, preocupando-se, quase que exclusivamente, em veicular e ensinar informações e valores. Claro que se aprende a pensar em muitos e diversificados lugares, mas só a escola pode fazê-lo de forma intencional e sistemática. (DAVIS; NUNES; NUNES, 2005, p. 29).
\end{abstract}

Assim, ter ciência sobre a metacognição e os motivos pelos quais ela é essencial no desenvolvimento de uma aprendizagem reflexiva é tarefa que se espera das instituições de ensino, principalmente as públicas, nas quais se encontram aqueles que mais necessitam de uma formação que os emancipe. Sobre isso, Portilho afirma que "[...] ao realizar-se a reflexão da reflexão, faz-se referência à complexidade do pensamento humano que surge da reflexão sobre o conhecimento produzido" (2006, p. 49).

Também consideramos importante conceituar o que são estratégias, porque esse conceito será tratado com recorrência durante a análise. Solé expõe o conceito, afirmando que "[...] as estratégias são suspeitas inteligentes, embora arriscadas, sobre o caminho mais adequado que devemos seguir" (1998, p. 69). A autora complementa:

[...] a estratégia tem em comum com todos os demais procedimentos sua utilidade para regular a atividade das pessoas, à medida que sua aplicação permite selecionar, avaliar, persistir ou abandonar determinadas ações para conseguir a meta a que nos propomos. (SOLÉ, 1998, p. 69).

Argumentando na mesma direção, também Portilho (2006, p. 49) afirma que "[...] o conceito de estratégias de aprendizagem está relacionado a um conjunto de operações mentais que requerem planificação e controle na hora de serem executadas". Verificamos que ambas as autoras entendem a metacognição como um processo essencial, em que o sujeito, além de planejar seu processo de aprendizagem, também avalia esse processo.

Os autores citados nesta pesquisa entendem a metacognição e as estratégias metacognitivas como sendo de fundamental importância para o desenvolvimento da aprendizagem e resolução de problemas. Defendem que, quando o educando tem consciência e utiliza as estratégias metacognitivas, a aprendizagem se torna mais eficiente e significativa. Sendo assim, é imprescindível a compreensão de que a aprendizagem das estratégias metacognitivas é essencial para o desenvolvimento intelectual dos alunos, já que, 
de acordo com a pesquisa teórica realizada, essas estratégias não são inatas, necessitando ser ensinadas.

Após a apresentação dos conceitos acima, passaremos à descrição da pesquisa realizada com os professores. Posteriormente, realizaremos a análise das respostas do questionário, que pode nos dar um parâmetro de como os educadores desse estabelecimento de ensino público lidam com estratégias metacognitivas de leitura e como as aplicam aos seus alunos.

O questionário foi aplicado a onze professores, no mês de julho de 2016, sendo constituído por 6 questões, entre elas quatro abertas e duas fechadas. A maioria dos professores entregou logo após ter respondido e apenas alguns entregaram no dia seguinte. Já o professor de Artes concordou em participar, porém não entregou o questionário.

\section{A PESQUISA}

A seguir, apresentamos a descrição das respostas ao questionário, observando quais são as estratégias metacognitivas utilizadas pelos próprios professores durante suas leituras e, posteriormente, verificando como esses professores orientam seus alunos quanto ao uso das estratégias.

\section{Professor de Língua Portuguesa 1}

Esse professor diz que utiliza em suas leituras as seguintes estratégias: grifa o texto, destaca, faz anotações, consulta dicionários, relê o texto, recorre a outros textos sobre o mesmo assunto quando necessário, lê em voz alta, diminui a velocidade da leitura e ainda solicita auxílio a outra pessoa, quando necessário. Quando questionado se orienta seus alunos no uso dessas estratégias, o professor respondeu afirmativamente, porém não especificou quais delas ensina aos estudantes.

\section{Professor de Língua Portuguesa 2}

O professor de Língua Portuguesa 2 respondeu que faz uso das estratégias: grifa, destaca, faz anotações, paráfrases, consulta dicionário, relê, recorre a outros textos e diminui a velocidade de sua leitura. Orienta os educandos a fazer anotações e paráfrases.

\section{Professor de Língua Portuguesa 3}

O educador disse que lança mão das seguintes estratégias: grifa, destaca, faz anotações, resumos, paráfrases, releitura do texto e ainda diminui a velocidade, quando necessário. A seus alunos, solicita que grifem, façam anotações e releiam.

\section{Professor de Matemática 1}

Esse professor respondeu que grifa, faz anotações, consulta dicionário, relê, diminui a velocidade da leitura se necessário, e ainda recorre a outros textos 
sobre o mesmo tema, se achar pertinente. Assim como o primeiro professor apresentado, respondeu que ensina essas estratégias aos alunos, mas não as especifica.

\section{Professor de Matemática 2}

O professor diz que utiliza duas estratégias para suas leituras: grifa e relê e orienta seus alunos para a releitura do texto.

\section{Professor de Inglês}

O professor de Inglês respondeu que utiliza as seguintes estratégias: grifa o texto, faz anotações e relê. Não especificou quais estratégias ensina aos alunos.

\section{Professor de História}

O professor de História declarou que, durante as leituras, recorre às seguintes estratégias: grifa, destaca partes do texto, consulta dicionário, relê e diminui a velocidade da leitura. Esse professor orienta os alunos a utilizarem uma estratégia: a releitura.

\section{Professor de Ciências}

O entrevistado respondeu que grifa, destaca, faz anotações, resumos, paráfrases, consulta a dicionários, relê, recorre a outros textos sobre o mesmo tema e diminui a velocidade da leitura. Também não especifica quais estratégias orienta seus alunos a seguir.

\section{Professor de Espanhol}

Esse participante da pesquisa relatou que destaca, faz anotações, resumos, consulta dicionários, relê, lê em voz alta e diminui a velocidade da leitura. Quanto a seus alunos, orienta-os a reler, ler em voz alta e a diminuir a velocidade.

\section{Professor de Geografia}

O professor de Geografia declarou que recorre às seguintes estratégias: grifa, destaca, faz anotações e resumos, relê, consulta dicionário, diminui a velocidade e recorre a outros textos. Orienta seus alunos a utilizar todas as estratégias citadas.

\section{Professor de Artes}

Esse participante não devolveu o questionário.

Com o intuito de termos uma percepção mais geral e panorâmica desses resultados, inserimos dois gráficos sobre a pesquisa. 0 gráfico 1 demonstra as 
estratégias que os professores utilizam, enquanto o gráfico 2 revela quais estratégias os professores ensinam aos alunos.

Gráfico 1

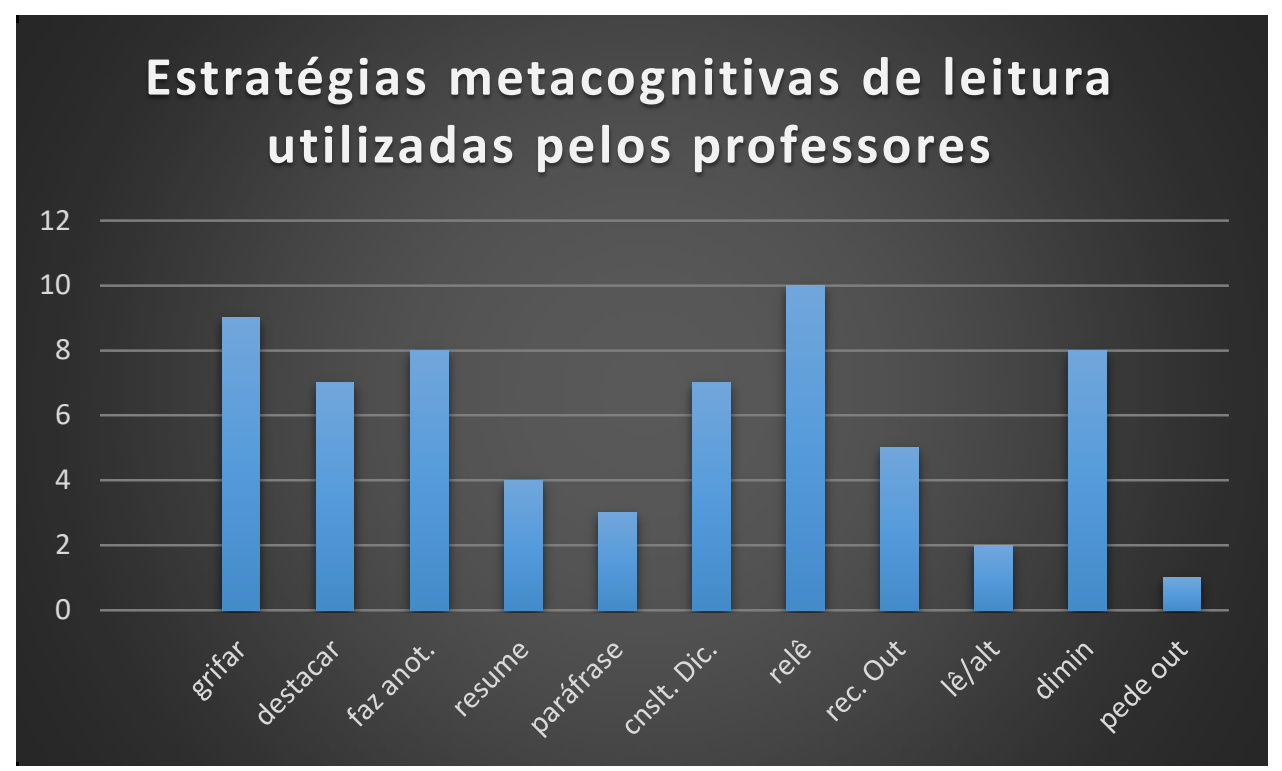

Fonte: elaboração própria

Gráfico 2

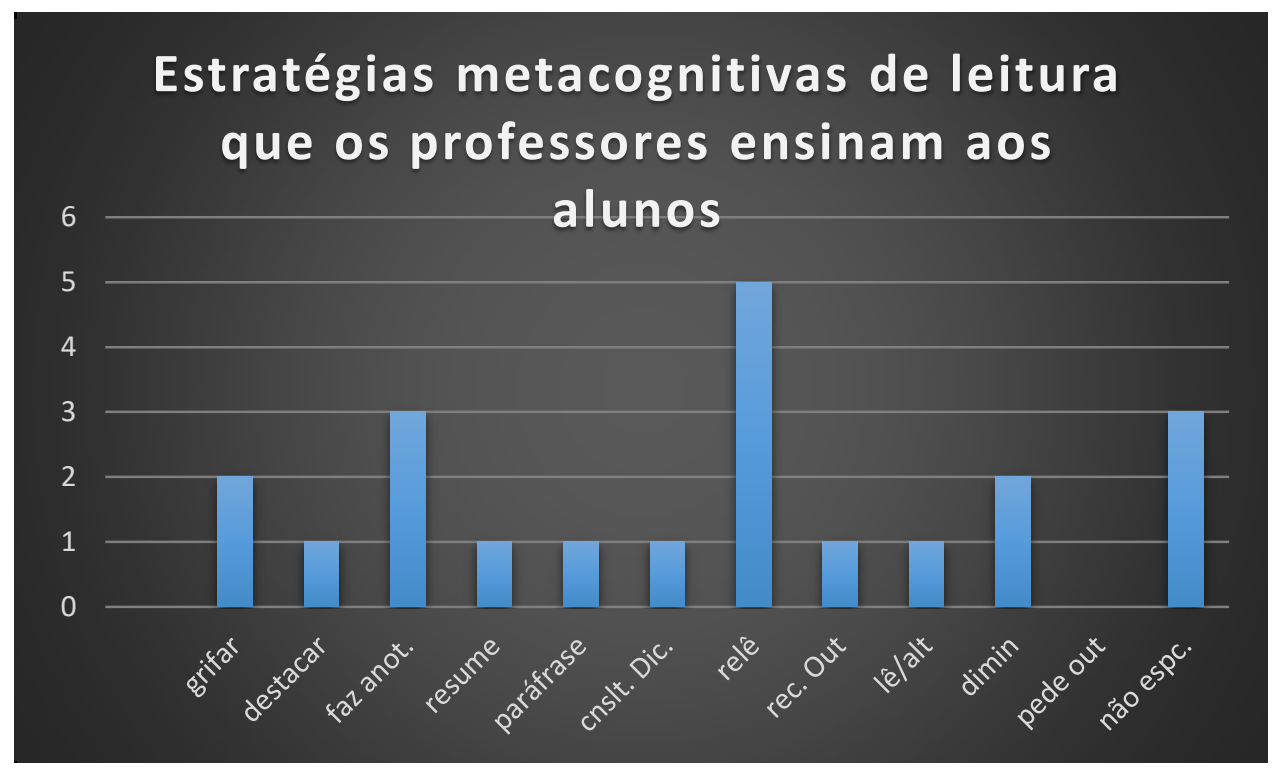

Fonte: elaboração própria

A partir dos dois gráficos, podemos notar que os professores utilizam de forma significativa as estratégias de leitura, desde as mais simples como grifar partes do texto, até outras mais inferenciais como a produção de resumos e paráfrases. Contudo, quando comparamos os gráficos, verificamos um pequeno trabalho no que diz respeito ao ensino dessas estratégias aos alunos, principalmente aquelas estratégias que têm como objetivo uma leitura que ultrapasse a decodificação textual como, por exemplo, a paráfrase e o resumo. A 
estratégia mais ensinada pelos educadores entrevistados é a da releitura. Dos dez professores que responderam ao questionário, cinco orientam os alunos a utilizarem a releitura a fim de obterem uma leitura compreensiva e mais significativa. Em segundo lugar, está a estratégia de grifar o texto.

Embora estas sejam estratégias metacognitivas importantes, não podemos nos esquecer de que, subjacentes a essas orientações, podem estar visões equivocadas de compreensão leitora. Primeiramente, não se está considerando que, para que haja compreensão leitora, é necessário que o leitor possua conhecimentos sobre o assunto, para que possa relacioná-los com o que está sendo lido. Em outras palavras, se o texto apresenta um alto grau de informatividade para o aluno, a repetição da leitura será de muita valia. Nesse caso, a mediação do professor, levantando questões que não são conhecidas ou indicando outras fontes, é de grande importância. Além disso, apenas solicitar a releitura do texto pode deixar implícita a ideia de que se está atribuindo exclusivamente ao aluno a incompetência pela não compreensão, desconsiderando que esta não está centrada nem no texto, nem no aluno, mas na interação entre leitor e autor, por meio do texto, como nos alerta Koch e Elias (2007).

Entendemos que o ensino dessas estratégias possui um papel significativo para o desenvolvimento da leitura. Por esse motivo, é importante que os educadores entendam as estratégias metacognitivas como parte do ensinoaprendizagem de leitura e, consequentemente, assumam sua contribuição na formação de leitores proficientes. Como afirma Solé (1998, p. 70), "[...] se as estratégias de leitura são procedimentos e os procedimentos são conteúdos de ensino, então é preciso ensinar estratégias para a compreensão dos textos".

Também Portilho (2006) apresenta um questionamento interessante sobre o ensino acerca do desenvolvimento da metacognição, afirmando que "[...] hoje se fala muito que uma das metas do processo aprendizagem-ensino é estimular o aprendiz a ser autônomo, isto é, sujeito do seu próprio aprender. E a autora se pergunta: isso pode ser ensinado?" (, 2006, p. 48). O questionamento da autora sobre a aprendizagem de estratégias de metacognição é pertinente e pode ser pensado a partir das observações de Solé, referindo-se às estratégias metacognitivas: "[...] estas não amadurecem, nem se desenvolvem, nem emergem, nem aparecem. Ensinam-se - ou não se ensinam - e se aprendem - ou não se aprendem" (SOLÉ, 1998, p. 70). Nesse sentido, é imprescindível para a compreensão leitora dos alunos que a aprendizagem das estratégias metacognitivas seja, de fato, considerada como essencial nesse processo.

\section{CONSIDERAÇÕES FINAIS}

Percebemos, a partir desta pesquisa, que todos os dez participantes recorrem a estratégias metacognitivas para um melhor desempenho em suas leituras. Vale reforçar que essas estratégias devem ser ensinadas a fim de que os educandos possam, por meio delas, tornar-se mais independentes em relação à condução de seu próprio aprendizado, afinal 
convidá-la, conscientemente, a mudar quando for necessário melhorar sua aprendizagem. (PORTILHO, 2006, p. 48).

Nesse sentido, consideramos também as palavras de Leffa (1996, p. 53), para quem "[...] a correlação positiva entre consciência das estratégias e proficiência em leitura é pelo menos uma boa indicação de que os leitores são capazes de analisar metacognitivamente seu comportamento lectural".

No entanto, há um fator discrepante evidenciado na pesquisa, que deve ser observado. Se compararmos a quantidade de estratégias utilizadas pelos educadores com as estratégias que ensinam, esse número fica relativamente baixo. Então, embora os professores tenham consciência das estratégias que utilizam, não orientam os alunos a utilizarem principalmente aquelas mais importantes, que levam a inferências, como os resumos e as paráfrases.

É importante lembrar, como nos alerta Leffa (1996), que, embora as estratégias metacognitivas sejam desenvolvidas naturalmente com a idade, certamente por meio da experiência com a leitura, também a experiência pedagógica pode modificá-las. Portanto, é inegável que o professor deva desempenhar um papel fundamental ao contribuir para que o aluno adquira autonomia para construir o sentido para sua leitura. 


\title{
Metacognitive strategies for reading in school
}

\begin{abstract}
This article aims to discuss some concepts related to metacognitive strategies of reading and presents the results of a research carried out with public school teachers from different subjects. The research developed was aimed to find what reading metacognitive strategies the participating teachers use while reading and whether these professionals teach these strategies to their students. The results were obtained through a written questionnaire. The research showed that all interviewees use metacognitive strategies when reading, although when it comes to teaching, the result suffered some variations.
\end{abstract}

KEYWORDS: Metacognitive strategies. Reading. Teaching. 


\section{REFERÊNCIAS}

DAVIS, Claudia. NUNES, Cesar A. A. NUNES, M.R. Marina. Metacognição e sucesso escolar: articulando teoria e prática. Cadernos de Pesquisa, v. 35. $n^{\circ} 125$, 2005, p.205-230.

KLEIMAN, Angela B. Leitura e interdisciplinaridade. Campinas: Mercado de Letras. 2007.

LEFFA, Vilson J. Aspectos da leitura. 1a. ed. Porto Alegre: Ed. Sagra- D.C. Luzzatto, 1996.

PORTILHO, Evelise Maria Labatuti. As estratégias metacognitivas de quem aprende e de quem ensina. Petrópolis: Vozes, 2006. p. 47-59.

RIBEIRO, Célia. Metacognição: Um apoio ao processo de aprendizagem. Psicologia: Reflexão e Crítica, 2003, 16 (1), pp. 109-116.

SOLÉ, Izabel. Estratégias de leitura. $6^{\circ}$ ed. Porto Alegre: Artemed, 1998.

Recebido: 24 jun. 2017

Aprovado: 07 set. 2017

DOI: $10.3895 /$ rl.v19n26.6060

Como citar: DONDONI, Angela; SANTOS, Maria Elena Pires. Estratégias metacognitivas de leitura na escola. R. Letras, Curitiba, v. 19, n. 26, p. 76-85, set. 2017. Disponível em:

<https://periodicos.utfpr.edu.br/rl>. Acesso em: XXX.

Direito autoral: Este artigo está licenciado sob os termos da Licença Creative Commons-Atribuição 4.0 Internacional.

\section{(c) (1)}

